\title{
Simulation Modelling of Market of Derivative Financial Instruments
}

\author{
Olena Stashchuk, Nataliia Bazhanova, Maksym Marych, Liubov Shevtsiv, Olena Tarasova, Olga \\ Purtskhvanidze
}

\begin{abstract}
The complexity and complexity of the derivatives market requires a special approach to analysis and forecasting. To this end, the article discusses the method of simulation of the derivatives market using open-source software.

The article describes the approach to creating a model simulating the behaviour of agents in the derivatives market. Possible options for setting parameters and tracking changes in key indicators are described.

The model complex for simulating the work of the market of derivatives described in the article is also possible to implement using software methods and implement it in other algorithms, without compromising its functionality. The article describes the modelling of standard situations in the market, however, the flexibility of settings allows you to simulate any necessary task.
\end{abstract}

Keywords : Derivative Financial Instruments,Financial Market, Modelling, Simulation.

\section{INTRODUCTION}

The importance of the task of modeling the stock market when using derivative financial instruments is determined by the complexity and complexity of the laws of operation and patterns of behavior of the stock exchange, its reaction to collapses and the formation of "bubbles", taking into account the behavior of players both in stable operation and in a crisis.

The complexity of the mathematical modelling of the derivatives market is due to:

1) the need for an adequate description of the uncertainty inherent in the behaviour of market participants;

2) the need to take into account assumptions about statistical patterns that are difficult to identify, confirm and theoretically substantiate;

3) the need to take into account the huge amount of dynamically changing information;

4) the inability to use the forecasts and predictions of financial analysts (due to their frequent fallibility) in assessing the parameters of the model;

5) the complexity of taking into account the possibilities of crisis;

6) the complexity of describing the mechanisms of

Revised Manuscript Received on November 25, 2019.

* Correspondence Author

Olena Stashchuk*, the Finance and Credit Department, Lesya Ukrainka Eastern European National University, Lutsk, Ukraine

Nataliia Bazhanova, Department of Economics and Finance, Ternopil Ivan Puluj National Technical University, Ternopil, Ukraine

Maksym Marych, Department of Public, Corporate Finances and Financial Mediation, Yuriy Fedkovych Chernivtsi National University, Chernivtsi, Ukraine

Liubov Shevtsiv, Department of Accounting and Auditing, Ivan Franko National University of Lviv, Lviv, Ukraine

Olena Tarasova, Department of Accounting and Auditing, Odessa National Academy of Food Technologies, Odessa, Ukraine

Olga Purtskhvanidze, Department of Management and Logistic, Odessa National Academy of Food Technologies, Odessa, Ukraine influence and accounting for the varying degrees of influence of large and small participants on the dynamics of exchange indicators [1-5].

In modern realities characterized by high volatility of interest rates, fluctuations in exchange rates and prices, as well as increasing financial risks, the use of derivative financial instruments (derivatives) is of particular value. The active development of the derivatives market not only united the global financial market but also became a mechanism for massive redistribution of capital from one sphere to another. It should be remembered that the use of derivatives is not just speculation on the stock exchange, but an effective method of managing financial risks [6-9].

In general, the model of the derivatives market can be schematically represented inFig.1.

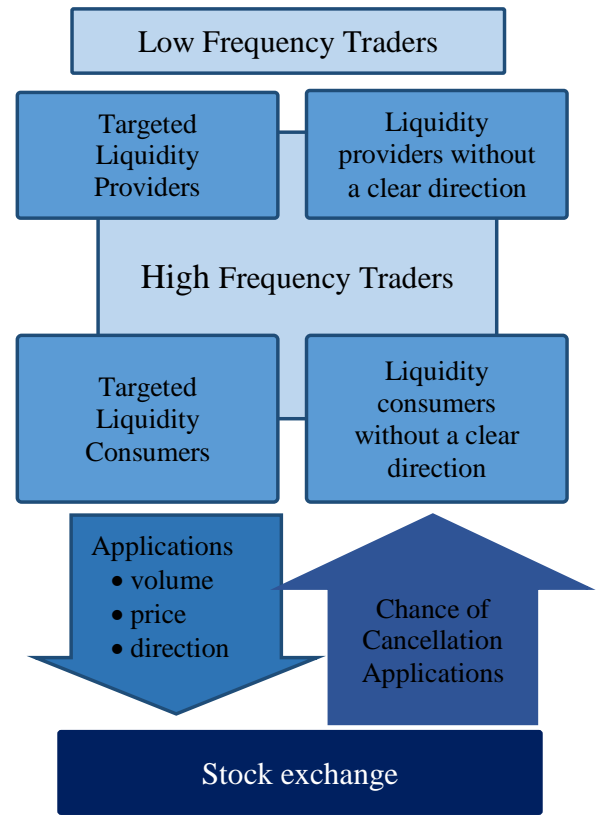

Fig. 1.Derivatives market work scheme

\section{METHODOLOGY}

It is important to understand that the role of derivatives in reducing risks is ambiguous. On the one hand, hedging operations contribute to the integration of different segments of financial markets and allow the redistribution of risks. On the other hand, speculative motives prevail in transactions with derivatives, and a small amount of invested capital can bring both significant profits and significant losses. Therefore, a special role in this is played by the ability to simulate the behaviour of the market in various conditions and predict the ways of its development.

The methodology of simulation of the derivatives market for hedging financial risks should take into account market specifics. 


\section{A. Basic factors for creating a model}

An analysis of derivatives markets allows us to identify several features of the use of derivative financial instruments in international companies:

- hedging of risks using derivatives is typical for companies in small but well-developed economies with a low share of international trade;

- derivatives for hedging financial risks are actively used by companies in those countries where they are poorly protected by civil law;

- firms with large sales and revenues in foreign currency occupy large positions in foreign exchange derivatives;

- firms that use derivatives on interest rates apply greater leverage (leverage).

Schematically, the main features of working with derivatives are presented in Fig. 2.

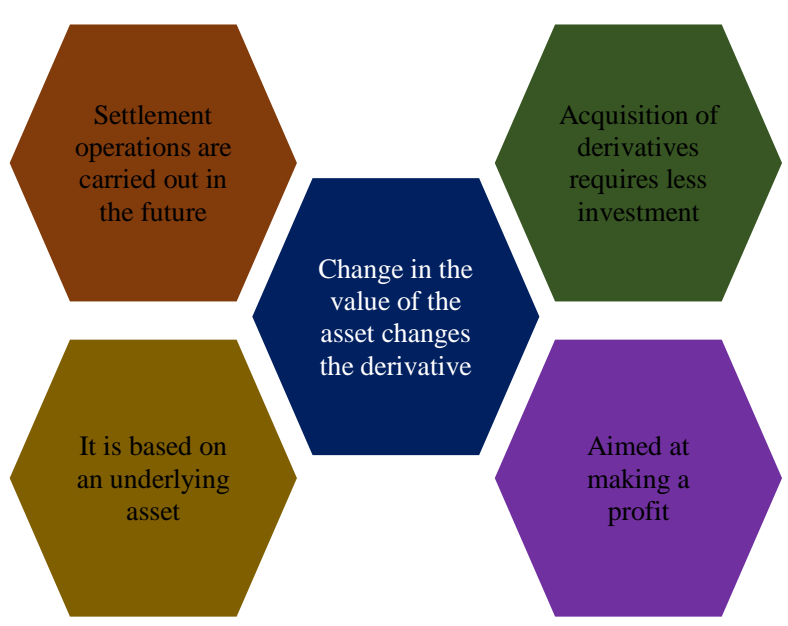

Fig. 2.Key features of derivatives

As part of this work, the task was set to form a system that imitates the process of pricing in the market. Such a system can be used to test various trading strategies, as well as to test various hypotheses regarding stocks of a particular company or a specific stock index (for example, DJIA) due to the possibility of flexible selection of system parameters.

Modelling the market for derivative financial instruments can be based on the consideration of participants in the financial market as limited-rational adaptive agents, which is essentially a flexible methodology for modelling such complex systems and their behaviour.

We take for the hypothesis that in the simulated system, there are two types of agents: fundamental analysts and technical analysts, the variables nf and nt determine their ratio in the system, respectively:

$$
n t+n f=1
$$

Fundamentalists decide on the price of derivatives based on news related to an organisation that issues securities to develop and finance their activities. News in its essence is unpredictable, and you can imagine their movement as a random geometric walk. $\ln \left(V_{t}\right)$ - a variable simulating the process of the random walk:

$$
\ln \left(\frac{V_{t}}{V_{t}-1}\right) \sim N(0.0013,0.023)
$$

$\ln \left(\frac{V_{t}}{V_{t}-1}\right)>0$ means good news, $\ln \left(\frac{V_{t}}{V_{t}-1}\right)<0$ means bad news

In this case, the fundamental return on the asset at the time between $t$ and $t+1$ :

$$
F_{t}=r \ln \left(\frac{V_{t}}{P_{t}}\right)
$$

where $P_{t}$ is the price of the derivative at a given moment in time $\mathrm{t}$, and $\mathrm{r}$ takes

value according to the following rule:

$$
\left\{\begin{array}{c}
1.1 \text { if } V_{t}>V_{t-1}>V_{t-2}>V_{t-3} \text { or } \\
V_{t}<V_{t-1}<V_{t-2}<V_{t-3} ; \text { else } \\
1 \text { if } V_{t}>V_{t-1}>V_{t-2} \text { or } \\
V_{t}<V_{t-1}<V_{t-2} ; \text { else } \\
0.9
\end{array}\right.
$$

Technical analysts make a decision based on the trend, i.e. based solely on observed prices in the past. In this system, they look at the previous three days and calculate the technical yield of the derivative at a time between $t$ and $t+1$ using the following formula, which in essence is a sliding window:

$$
T_{t}=c^{3} \ln \left(\frac{P_{t-2}}{P_{t-3}}\right)+c^{2} \ln \left(\frac{P_{t-1}}{P_{t-2}}\right)+c \ln \left(\frac{P_{t}}{P_{t-1}}\right)
$$

where $c=0.544$ is the root of the equation $\mathrm{c} 3+\mathrm{c} 2+\mathrm{c}=1$, the purpose of which is to give prices different significance: the newer the price, the greater its weight. Instead of the price of a derivative, one can consider profitability, i.e. derivative logarithmic increment. Then the new value of the yield of the derivative is calculated by the following formula:

$$
\ln \frac{P_{t+1}}{P_{t}}=n_{f} F_{t}+n_{t} T_{t}
$$

\section{B. Implementation of a warrant system model and heterogeneity modelling}

We add to the model an imitation of the ability to buy/sell one unit of the derivative, and this happens if the current price is lower than $\backslash$ higher than what is expected in the future (therefore, it is also necessary to introduce an additional variable that determines the mathematical expectation of the price the next day).

Since fundamentalists are much less likely to bid, the special parameter $\mathrm{K}$ is introduced. The fundamentalist becomes active only if the difference between the current price and the price he expects is greater than this parameter. What will be modelled through the formula:

$$
W(x)=x^{-(1+a)}
$$


To add heterogeneity among technical analysts, in the definition of T_t, introduce various values of the memory length $\mathrm{M}$ and evenly distribute them between the agents:

$$
T_{t}=c \sum_{i=1}^{M} c^{i-1} \ln \left(\frac{P_{t-i+1}}{P_{t-i}}\right)
$$

where the smoothing parameter $\mathrm{c}$ is determined for each agent individually in accordance with the value of the memory length.

To model heterogeneity among fundamental analysts, it is proposed to add the noise parameter $\mu$, an independent random variable with a zero mean value, to the definition of $F_{t}$.

$$
F_{t}=r \ln \left(\frac{V_{t}}{P_{t}}\right)+\mu
$$

The heterogeneity in predicting the price of a derivative the next day can be realized through the parameters reactf and reactt, which will mean an estimate of the speed with which the price tends to its fundamental value among fundamental analysts, and the sensitivity of technical analysts to price changes, respectively.

Additional heterogeneity can be given to the behaviour of agents, with the introduction of a model of simulation noise parameters $\sigma, \tau, \beta$ in determining prices by a market maker and the mathematical expectation of prices from fundamental and technical analysts:

$$
\begin{aligned}
& E_{t}^{f}\left(P_{t+1}\right)=P_{t}+\text { react }_{f} *\left(F_{t}-P_{t}\right)+\tau \\
& E_{t}^{t}\left(P_{t+1}\right)=P_{t}+\text { react }_{t} *\left(P_{t}-T_{t}\right)+\beta \\
& P_{t+1}=P_{t} *\left(1+a *\left(D_{t}-S_{t}\right)\right)+\sigma
\end{aligned}
$$

where $a$ is the coefficient that regulates the price, and $D_{t}$ and $S_{t}$ are the number of buy and sell orders.

Typically, the purpose of buying a derivative is not to physically obtain the underlying asset, but to hedge price or currency risk over time or to obtain speculative profit from changes in the price of the underlying asset. The final financial result for each side of the transaction can be either positive or negative. That is why the model was based on the pricing principle.

\section{EXPERIMENT}

The system described was implemented as a software module in the RStudio environment.

RStudio is a free open source software development environment in the $\mathrm{R}$ language, which is designed for convenient and flexible statistical processing of data and graphics.

In the process of testing, multiple simulations of 1000 trading days were carried out with a different ratio of fundamental and technical analysts. In order to visually evaluate the values of various statistical indicators, a visual analysis of statistics and a comparison of stylized facts were carried out.

The average value and the standard deviation of the yield are realistic for $30 \%-70 \%$ of the technical agents in the system, as shown in the graphs of Fig.3.
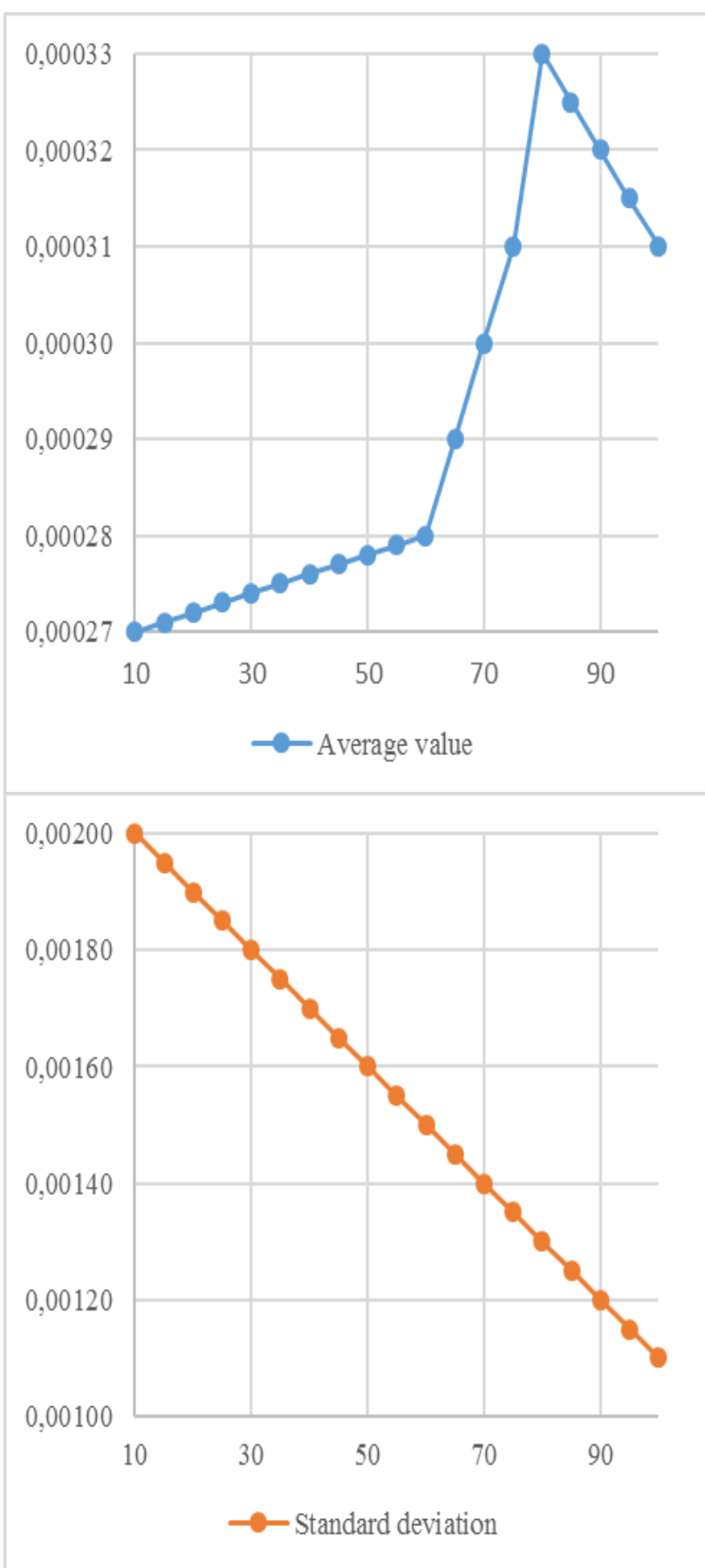

Fig. 3. The average value and standard deviation of profitability for a given number of technical specialists in the model

However, as can be seen from Fig. 4 despite the fact that the system was able to simulate the time series of quotes, in which there are statistics that reflect such stylized facts as the average value, standard deviation, autocorrelation of squares and absolute values at $30 \%-50 \%$ of technical analysts in the model, still it was possible to achieve values of autocorrelation, asymmetry, and excess, which could be considered correct from the point of view of empirical calculations. 


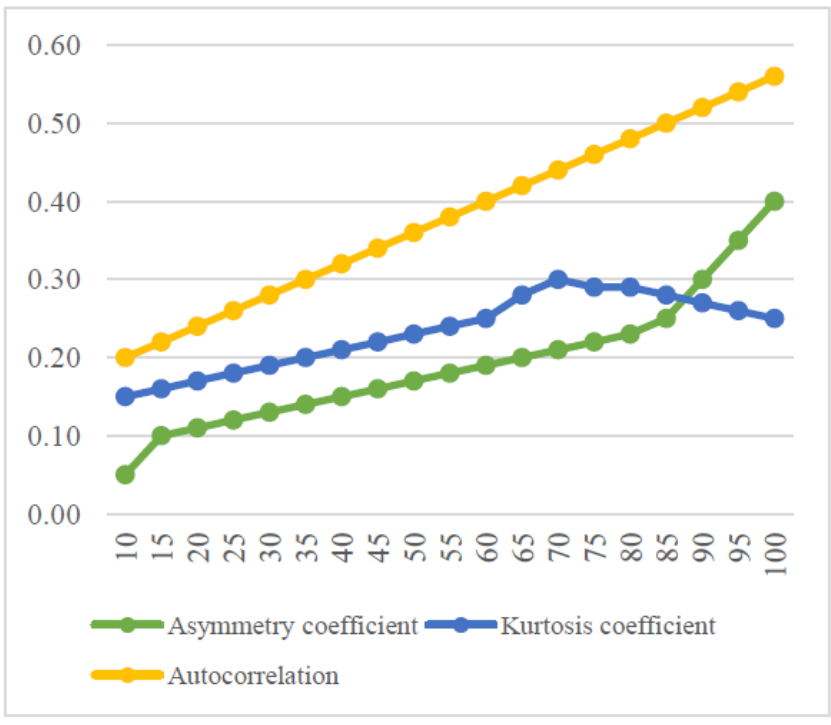

Fig. 4.Statistical indicators for the asymmetry coefficient, kurtosis coefficient and autocorrelation

Therefore, the next step was the addition of an order system to the model and heterogeneity modelling.

In addition to the $n f$ and $n t$ parameters, other free parameters appeared, thanks to which it is possible to endow the system with new properties and adjust the behaviour of agents in the model.

\section{RESULT AND DISCUSSION}

Combining various valuesof free parameters, in addition to stylised facts, it is also possible to achieve numerically close statistical indicators, using various measures of proximity (distance metrics) for analysis. The model parameters for the experiment are presented in Table 1.

Table- I: The parameters of the simulation model of the derivatives market \begin{tabular}{|l|l|}
\hline Parameters & Value \\
\hline
\end{tabular}

\begin{tabular}{|c|c|}
\hline Parameters & Value \\
\hline Price adjusting parameter (a) & $0,2 * 10-4$ \\
\hline Fundamentalist activation parameter (K) & $5 \%$ \\
\hline Parameter in Power Law ( $\boldsymbol{\alpha})$ & 1,5 \\
\hline Smoothing parameter ( $\mathbf{c})$ & {$[0.3,0.99]$} \\
\hline Fundamentalist reaction rate (reactf) & $\mathrm{N}(0: 04 ; 0: 04)$ \\
\hline Chartist reaction rate (reactt) & $\mathrm{N}(0: 05 ; 0: 04)$ \\
\hline Noise standard deviation $\boldsymbol{\mu}$ & 0,026 \\
\hline Noise standard deviation $\boldsymbol{\sigma}$ & 0,025 \\
\hline Noise standard deviation $\boldsymbol{\tau}$ & 0,01 \\
\hline Noise standard deviation $\boldsymbol{\beta}$ & 0,05 \\
\hline Memory parameter (M) & $(1,50)$ \\
\hline
\end{tabular}

To identify the presence or absence of stylised facts, we constructed graphs of all the statistics listed above with a different percentage of technical analysts in the model and repeated startup of the system.

Fig. 5 and fig. 6 show the results of testing the final system. It can be noted that there is a pronounced positive coefficient of kurtosis and a small negative autocorrelation, which was not observed in the model constructed by the base system.

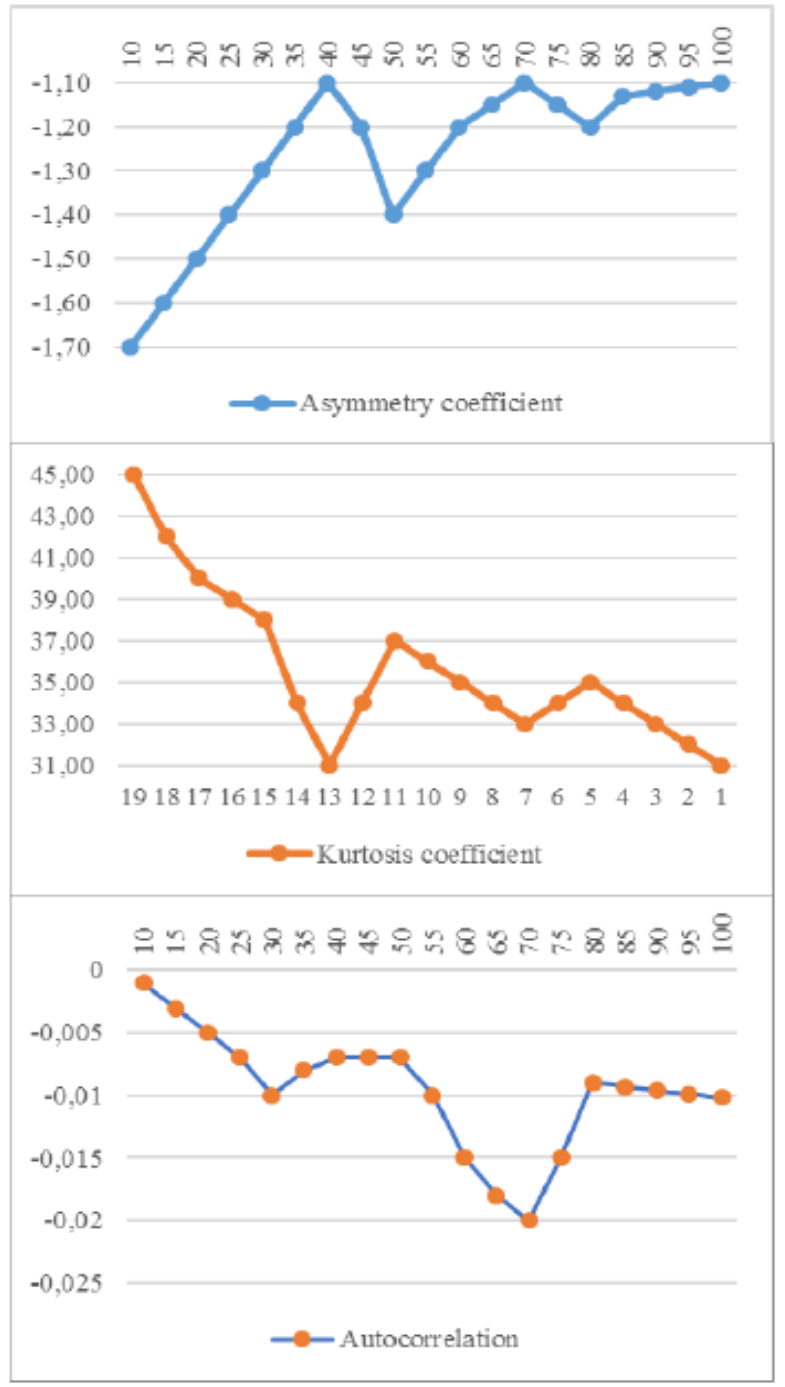

Fig. 5. Average value deviation of profitability for the model

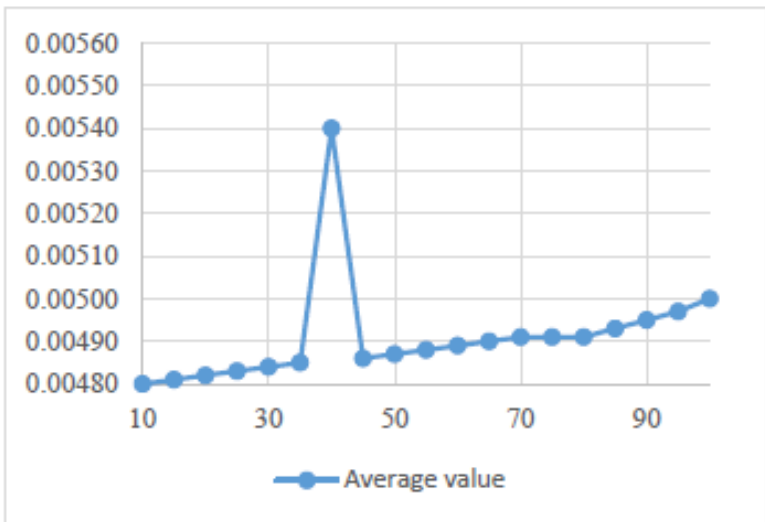

Fig. 6. Graphs mean value, standard deviation, and autocorrelation of absolute values

The mean value, standard deviation, and autocorrelation of the absolute values presented in fig. 6 retained their real values. The asymmetry coefficient still retains its negative value, which on the one hand does not coincide with the stylised fact, but on the other hand it is observed in the statistics of real derivatives

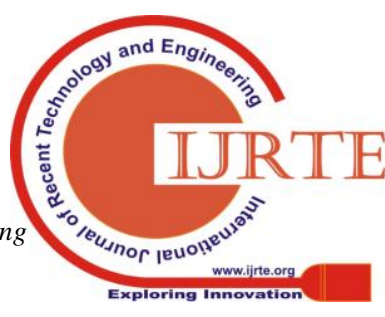


markets. If necessary, you can adjust the asymmetry so that it also reflects the stylised factor.

In the derivatives market model supplemented by elements of an order system and modelling heterogeneity factors, it can be noted that the most successful statistical indicators are obtained if $40 \%$ of the market participants are technical analysts. This percentage falls into the range [30\%-50\%], which was obtained by analysing the results of the base system.

As a comparison, we present a table of summary data of statistical data of the base and final versions of the derivatives market model, Table 2 .

Table- II: Statistical data of the base and final versions of the derivatives market model

\begin{tabular}{|c|c|c|}
\hline Statistics & Base Model & Final Model \\
\hline Average & $2.747364 \mathrm{e}-04$ & $5.53097 \mathrm{e}-05$ \\
\hline Standard deviation & 0.01653036 & 0.004983651 \\
\hline Asymmetry coefficient & 0.1573943 & -0.9796748 \\
\hline Kurtosis coefficient & 0.2153644 & 32.03579 \\
\hline Autocorrelation & 0.5522113 & -0.01685278 \\
\hline Autocorrelation modulo & 0.26030875 & 0.5788605 \\
\hline Autocorrelation of squares & 0.27409132 & 0.4374577 \\
\hline
\end{tabular}

Similar indicators indicate the reliability of the presented models, while in combination with the graphs of autocorrelation and excess, it is clear that the final version more fully simulates the situation.

\section{CONCLUSION}

This paper presents a system that allows you to create simulation models of derivatives markets. With the help of settings and selection of parameters, using it you can recreate the profitability of real trading indices or individual companies. Such a system can be used to test various trading strategies, as well as to test various hypotheses concerning the stocks of a particular company or in relation to a specific stock index or derivative.

Also, the software implementation of the model algorithm will allow its use in other software products, combining or supplementing them.

\section{REFERENCES}

1. Danylyshyn, B., Bondarenko, S., Malanchuk, M., Pylypiv, V., Usachenko, O., Method of real options in managing investment projects, International Journal of Innovative Technology and Exploring Engineering, 8(10), 2019, pp. 2696-2699.

2. Zabihollah Rezaee, Derivative Financial Instruments In book: Financial Services Firms: Governance, Regulations, Valuations, Mergers, and Acquisitions, Third Edition, January 2012, DOI: 10.1002/9781118269169.ch18

3. Prokopenko, O., Eremenko, Y., Omelyanenko, V., Role of international factor in innovation ecosystem formation, Economic Annals-XXI, 3-4, 2014, pp. 4-7

4. S. Shaowen, Effect of derivative financial instruments on the financial risk of enterprises, April 2015, DOI: 10.5013/IJSSST.a.16.2B.05

5. Oles Gruzdev, Derivative financial instrument in the system of civil contracts, June 2018, DOI: 10.17223/22253513/28/12

6. Kátia Matos Lemos, Sara Serra, Amidel Barros, The Auditor as a Determining Factor on Derivative Financial Instrument DisclosuresIn book: Organizational Auditing and Assurance in the Digital Age January 2019, DOI: 10.4018/978-1-5225-7356-2.ch004

7. V.S. Lukianov, Derivative financial instruments as a product of financial engineering, Actual Problems of Economics, 153(3), 2014, pp. $431-437$ 